\title{
Construction of Oryza sativa genome contigs by finger- print strategy
}

\author{
TAO Quanzhou ${ }^{\# *}, Y_{\text {umin }} \mathrm{QIAN}^{\# *}, \mathrm{H}_{\mathrm{i} i \mathrm{ing}}$ \\ ZHAO*, Shulang YU*, Longfang QIU*, Boqian \\ WU*, JIA ZHU*, D I YU*, XIAOHUI LIU*, GUOFAN \\ $\mathrm{HONG}^{* * 1}$ \\ * National Center for Gene Research, Chinese Academy \\ of Sciences, Shanghai 200233, China. \\ ** Shanghai Institute of Biochemistry, Chinese Academy \\ of Sciences, Shanghai 200031, China.
}

\begin{abstract}
We described the construction of BAC contigs of the genome of a indica variety of Oryza sativa, Guang Lu Ai 4. An entire representative (sixfold coverage of rice chromosomes) and genetically stable BAC library of rice genome constructed in this lab has been systematically analysed by restriction enzyme fragmentation and polyacrylamide gel electrophoresis. And all the images thus obtained were subject to image-processing, which consisted of preliminary location of bands, cooperative tracking of lanes by correlation of adjacent bands, a precise densitometric pass, alignment at the marker bands with the standard, optional interactive editing, and normalization of the accepted bands. The contigs were generated based on the Computer Software specially designed for genome mapping. The number of contigs with $600 \mathrm{~kb}$ in length on average was 464; of contigs with $1000 \mathrm{~kb}$ in length on average was 107; of contigs with $1500 \mathrm{~kb}$ in length on average was
\end{abstract}

1. Corresponding author

\#. First authors

Abbreviations: $\mathrm{BAC}=$ bacterial artificial chromosome; Solution $\mathrm{I}=50 \mathrm{mM}$ glucose, 10 $\mathrm{mM}$ EDTA, $25 \mathrm{mM}$ Tris-HCl, $\mathrm{pH}$ 8.0; Solution II $=0.2 \mathrm{~N} \mathrm{NaOH}, 1.0 \%$ SDS; Solution III $=$ $60 \mathrm{mM} 5 M$ potassium acetate, $28.5 \mathrm{ml}$ glacial acetic acid, $11.5 \mathrm{ml}$ water, $\mathrm{pH} 4.8 ; \mathrm{TE}=10$ $\mathrm{mM}$ Tris-HCl, $1 \mathrm{mM}$ EDTA, $\mathrm{pH}$ 8.0; Multi-Core buffer $(10 \times)=250 \mathrm{mM}$ Tris acetate, $\mathrm{pH}$ 7.8 ( at $25{ }^{\circ} \mathrm{C}$ ), $1 \mathrm{M}$ potassium acetate, $100 \mathrm{mM}$ magnesium acetate, $10 \mathrm{mM}$ DTT. 
Construction of Oryza Sativa genome contigs

23. Therefore, all the contigs we have obtained amounted up to 420 megabases in length. Considering the size of rice genome (430 megabased), the contigs generated in this lab have covered nearly $98 \%$ of the rice genome. We are now in the process of mapping the contigs to chromosomes.

Key words: Contig, genome, indica, oryza sativa, $B A C$.

\section{INTRODUCTION}

Rice is one of the most important food crops in the world. It serves as staple food for nearly half of the world population, who are largely living in developing countries. Rice has now also become a model plant among the cereals for molecular genetic studies. It is a diploid with $\mathrm{n}=12$ chromosomes, and has the genome of approx, $4.3 \times$ $10^{8}$ base pairs (bp) in length, the smallest genome of any monocots known[1]. Rice has a large germplasm collection of more than 120,000 accessions worldwide, can be regenerated from protoplasts[2] and has a high degree of transformation efficiency relative to other cereal species[3].

In recent years rice genome is intensively studied, and a striking progress has been made. Using the restriction fragment length polymorphism (RFLP), McCouch et al[4] successfully constructed the RFLP map in rice, more recently, a high resolution genetic linkage map of rice was constructed[5], where 1383 mixed DNA markers including genes were mapping on 12 linkage groups with the markers at average interval of 300bp. Genetic maps are very useful, especially for identification and evaluation of genes of useful traits.

We have been focusing on the construction of a contig map for the rice genome. The contig map is of tremendous importance for the following two reasons: (1) in fact, a contig map is an ordered library of cloned DNA fragments that covers all of the genome. Therefore, when adequate biological information has been made available, directly from the contig map could be obtained genes and /or DNA sequences of interest, which could then be further studied at the desired levels for the purpose of either improving the quality and yield of rice, or of our better understanding of the living phenomena in the plant kingdom; (2) The ultimate goal of a genome program is to determine the entire nucleotide sequence of the genome to unveil the genetic mysteries of an organism at the molecular level. Sequencing one by one all the ordered cloned DNA fragments of the contig map fulfils the task.

The purpose of this report is to describe the construction of contigs for the rice genome, based on the DNA restriction fingerprinting technique developed by Sulston et al[6, 7] with modifications in enzymatic reactions designed for fingerprinting analysis. A representative[8] and genetically stable BAC library of the genome of 
rice (Oryza sativa) Guang Lu Ai 4 was used throughout this work

\section{MATERIALS AND METHODS}

\section{Materials}

A representative[8] and genetically stable (data not published) BAC library of the genome of rice (Oryza sativa) Guang Lu Ai 4 was constructed in this Center. Individual clones were kept in stock medium in 96-well microtiter plates at $-70{ }^{\circ} \mathrm{C}$. Enzymes HandIII, HaeIII, Sau3AI, AMV reverse transcriptase and RNase were purchased from Sigma. Tryptone and Yeast extract were the Oxide Products. Tris base, acrylamide, bis-acrylamide and TEMED were from Sigma. DNA sequencing apparatus (Sequi-GenII) was from BioRad. The computer software for genome mapping by fingerprinting was a kind gift from DR. Alan Coulson of the Sanger Center of Cambridge, UK. Patterns analysis was performed on UNIX Computer Working Station imported from the USA.

\section{BAC DNA preparation}

$5 \mu \mathrm{l}$ of each individual BAC stock was taken from the microtiter plates, and was inoculated into $5 \mathrm{ml}$ of $\mathrm{LB}$ medium containing $12.5 \mu \mathrm{g} / \mathrm{ml}$ of chloramphenicol. The BACs were incubated at $37{ }^{\circ} \mathrm{C}$ overnight with rotating at speed of $200 \mathrm{rpm}$. the culture was centrifuged at $600 \mathrm{rpm}$ for $10 \mathrm{~min}$. The cell pellet was resuspended in $0.2 \mathrm{ml}$ Solution I, to which $0.4 \mathrm{ml}$ of solution II was added. After well mixing and leaving on ice for $5 \mathrm{~min}, 0.3 \mathrm{ml}$ of Solution III was added and gently vortexed. The mixture was freezed at $-70{ }^{\circ} \mathrm{C}$ for $30 \mathrm{~min}$, and then was left at room temperature for slow thrawing. The solution was centrifuged for $15 \mathrm{~min}$ in a microfuge $(12,000 \mathrm{~g}), 0.75 \mathrm{ml}$ of the supernatant was carefully removed and transferred into a clean microfuge tube, to which 0.45 $\mathrm{ml}$ of isopropanol was added. After thoroughly mixing, the solution was placed at $-70{ }^{\circ} \mathrm{C}$ for 30 min, then was left to warm to room temperature. The DNA was pelleted by centrifugation in a microfuge for $5 \mathrm{~min}$. DNA thus obtained was rinsed with $\mathrm{lml}$ of cold $70 \%$ ethanol, and dried, and dissolved in $40 \mu \mathrm{l}$ of $\mathrm{TE}$, from which $3 \mu \mathrm{l}$ was taken for fingerprint analysis.

\section{Mapping gel}

The mapping strategy adopted in this work was based on that developed by Sulston et al[6, 7, 9] with modifications. The original multistep enzymatic reactions for generating ${ }^{32} \mathrm{P}$ labeled DNA fragmemts for fingerprint analysis were simplified by this lab into a single one, thus greatly shortening the time required for each cycle of data analysis, and enhancing the overall efficiency of the strategy for contig map construction. $3 \mu \mathrm{l}$ (50-100ng) of DNA was placed in a $0.5 \mathrm{ml}$ microfuge tube on ice, to which was added the equal volume of the mixture, that consists of $128 \mu \mathrm{l}$ of water, $39 \mu \mathrm{l}$ of Multi-core buffer, $4 \mu \mathrm{l}$ of HindIII $(50 \mathrm{U} / \mathrm{ml}), 4 \mu \mathrm{l}$ of HaeIII $(50 \mathrm{U} / \mu \mathrm{l}), 5 \mu \mathrm{l}$ of ddGTP $(0.5 \mathrm{mM})$, $5 \mu \mathrm{l}$ of AMV reverse transcriptase $(10 \mathrm{U} / \mu \mathrm{l})$ and $4 \mu \mathrm{l}$ of $\quad{ }_{-1}{ }^{32} \mathrm{P}$-dATP $(800 \mathrm{Ci} / \mathrm{mM})$. The reaction mixture was incubated at $37^{\circ} \mathrm{C}$ for $1.5 \mathrm{~h}$, to stop reaction, $3 \mu \mathrm{l}$ of the dye, containing Xylane cyanol FF $(0.1 \% \mathrm{w} / \mathrm{v})$ bromophenol blue $(0.1 \% \mathrm{w} / \mathrm{v})$ and EDTA $(0.3 \% \mathrm{w} / \mathrm{v})$ was added. All the components of the dye were dissolved in de-ionized formamide. Fractionation of the resulting fragment was performed on a $8 M$ urea $/ 4.0 \%$ denaturing sequencing gel. The markers DNA, which ran alongside with analyzed DNA fragments, was the Sau3AI digest products of lambda DNA, that were end labeled by $\quad{ }_{-}^{32} \mathrm{P}$ - dATP. The gel was run for $110 \mathrm{~min}$ at $85 \mathrm{~W}$ until the bromophenol blue is about $4 \mathrm{~cm}$ from the bottom of the gel. The gel was then dried at $90{ }^{\circ} \mathrm{C}$ in a vacuum gel drier, and was autoradiographed for $48 \mathrm{~h}$ without intensifying screen. On average, there were 30 discrete bands generated per BAC clone for fingerprint analysis.

\section{Image analysis}

The software in ANSI-C programming language is currently run on a Sun sparcstation 10 with SunOS4.1.3 operating system and SGI indigo 2 with IRIX 5.2 System. The data is entered by 


\section{Construction of Oryza Sativa genome contigs}

Scanning the autorad film and interpreted by an image-processing system. Graphics workstations are used for viewing, editing and analyzing the processed data. Scanning on the Sharp JX-610 transparent. Scanner is controlled by the program PhotoStyler. The image data is transfered to a SGI indigo 2 workstation. The program IMAGE loads the scanned mapping gel into memory, analyses the image, finds lanes, extracts bands and corrects for gel distortion. Accepted bands are automatically digitized, normalized and written to the database. The program Mapsub reads and matches every clone of a new subset against clones of the second subset. Matching involves counting within the preset tolerance the number of bands which span over the overlapping regions of clones. The program CONTIG is used for placing clones in contig. We depend on human judgement to decide the extents of overlap when contigs are being extended or joined. The verification of exact of overlaps was performed either by examination of the MAPSUB's output file MAP. OUT or by visual inspection of the films.

$$
\text { 20510-y8801(24b, 0) }
$$

$\begin{array}{lllll}15 \text { matches 80500-q1062 } & (20 \mathrm{~b}, 391) & 6.1 \mathrm{e}-12 & 18 & 9 \mathrm{~d} \\ 13 \text { matches 70280-w15442 } & (18 \mathrm{~b}, 391) & 3.6 \mathrm{e}-10 & 19 & 2 \\ 15 \text { matches60090-13845 } & (25 \mathrm{~b}, 391) & 6.1 \mathrm{e}-10 & 19 & 5 \\ 13 \text { matches 10360-t14497 } & (20 \mathrm{~b}, 391) & 2.7 \mathrm{e}-09 & 22 & 3 \\ 13 \text { matches 10581-t6884 } & (20 \mathrm{~b}, 391) & 2.7 \mathrm{e}-09 & 22 & 4\end{array}$

20510-y8803 (43b, 0)

$\begin{array}{lllll}23 \text { matches 70040-w18870 } & (32 \mathrm{~b}, 372) & 7.8 \mathrm{e}-12 & 27 & 20 \mathrm{~b} \\ 25 \text { matches 10320-t17519 } & (37 \mathrm{~b}, 372) & 8.5 \mathrm{e}-12 & 14 & 4 \\ 18 \text { matches 50350-b17583 } & (27 \mathrm{~b}, 372) & 1.0 \mathrm{e}-08 & 16 & 5 \\ 18 \text { matches 50350-b17585 } & (31 \mathrm{~b}, 372) & 23 \mathrm{e}-07 & 15 & 6 \\ 16 \text { matches 50342-b17582 } & (27 \mathrm{~b}, 372) & 7.4 \mathrm{e}-07 & 0 & 3 \\ 11 \text { matches 70420-w2578 } & (18 \mathrm{~b}, 0) & 5.7 \mathrm{e}-05 & 0 & 6 \\ 15 \text { matches 60200-11297 } & (33 \mathrm{~b}, 817) & 1.1 \mathrm{e}-04 & 18 & 5\end{array}$

Fig 1. Showing an example of one of the output forms.

From left: incoming clones, matching clones, probability of match Clearly, y8801 was internal in contig 391, and y8803 in contig 372.

\section{RESULTS}

We have analyzed the entire BAC library consisting 19660 BAC clones with average insert DNA of $120 \mathrm{~kb}$ in length, using the fingerprinting strategy developed by Sulston et al[6, 7, 9] with modifications in enzymatic reactions. Of $19660 \mathrm{BAC}$ clones 603 were found to be the repeats. Contig with lengths ranged from 600-1500 $\mathrm{kb}$ were obtained. The proportion of contigs with differing lengths can be seen in Fig 3. 
Tao QZ et al.

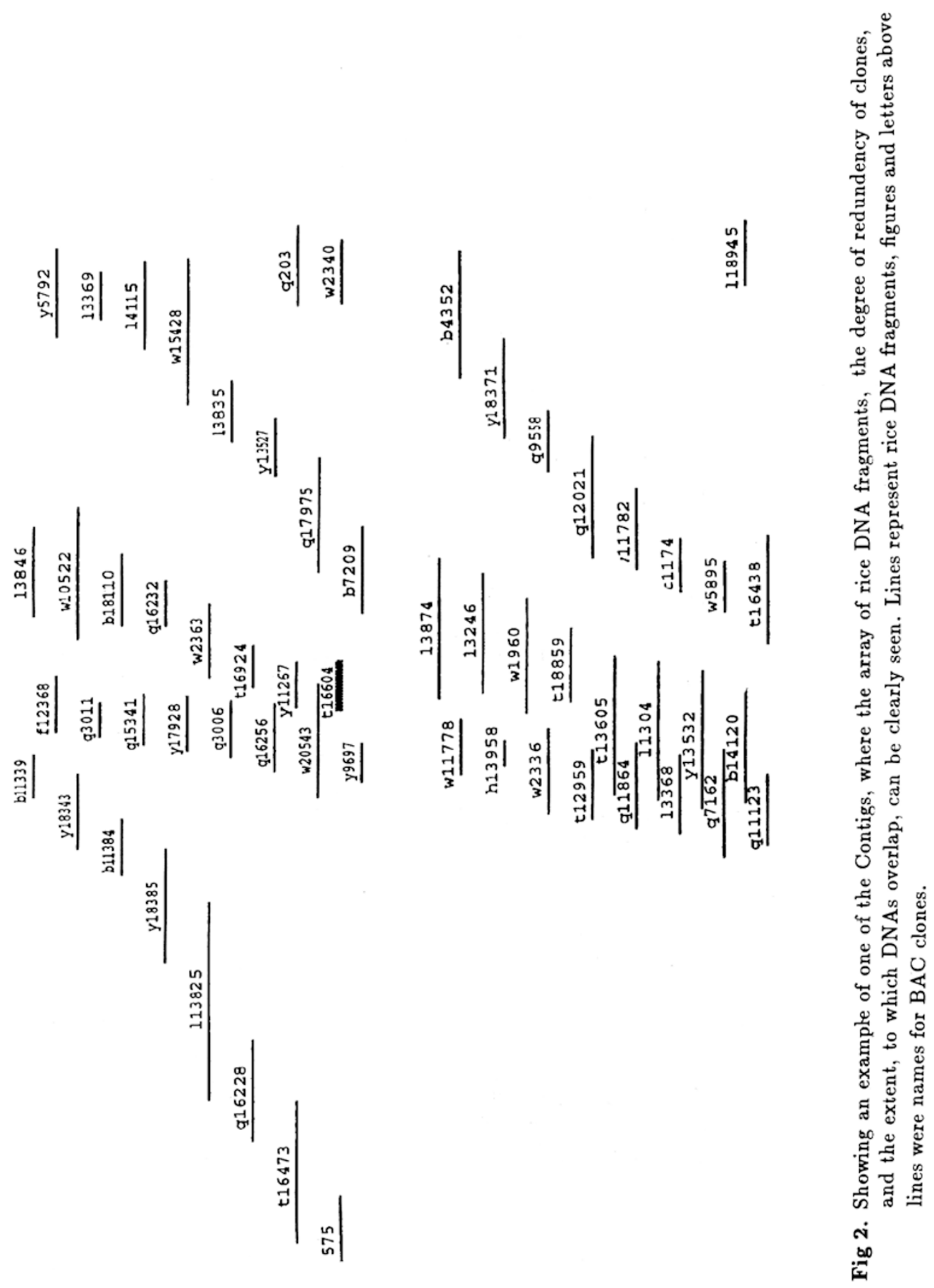




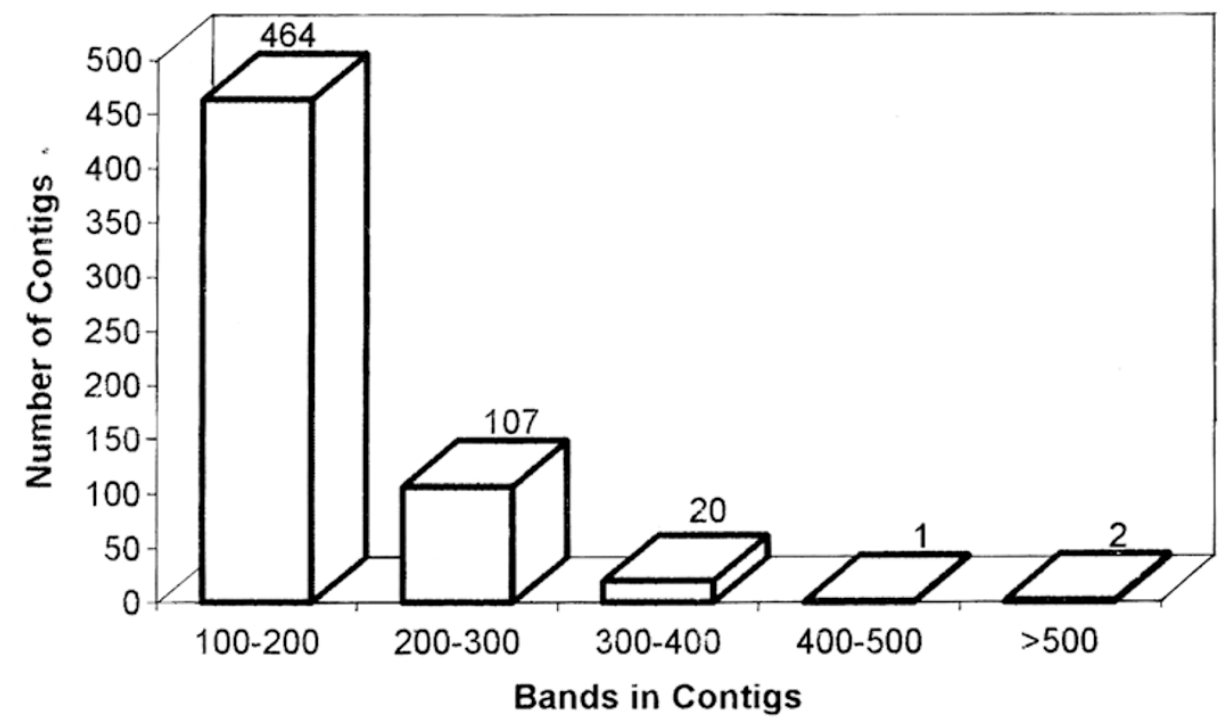

Fig 3. The proportion of contigs with differing lengths in our experiments, the average number of bands generated from single BAC clones was 30. Therefore, the length of a contig in $\mathrm{Kb}$ could be calculated by the equation, length of a contig=number of bands $/ 30 \times 120 \mathrm{~kb}$.

From the equation in Fig 3, the total length of contigs in $\mathrm{kb}$ could be calculated. We have obtained 464 clones with average number of bands of 150, 107 clones with bands of 250 and 23 clones with bands of 400 , i.e. they were $600 \mathrm{~kb} \times 464=278400 \mathrm{~kb}$, $1000 \mathrm{~kb} \times 107=107000 \mathrm{~kb}, 1500 \mathrm{~kb} \times 23=34500 \mathrm{~kb}$ respectively. The entire length of all contigs we have obtained was therefore 420 megabase, which covers nearly $98 \%$ of the rice genome (430 megabases). Tab 1 showed the details of same major contigs.

\section{DISCUSSION}

This was part of our project for contig map construction for the rice genome. In order to obtain accurate overlappings in contigs, we built up the contigs manually with one BAC clone added at a time in the similar manner as in the project for contig mapping for the C. elegance genome[6, 7, 9] . The use of combination of BAC-fingerprint strategy for contig construction has many advantages. It is most efficient to accumulate contigs; it produces contig maps with much fewer gaps than produced by using the strategy relying on genetic map; with the relatively smaller DNA insert in BAC, the contig maps produced have higher resolution, which will 
Tao QZ et al.

Tab.1 Details of some major contigs.

\begin{tabular}{|c|c|c|c|}
\hline Name of Contig | & Number of Bac Clone | & Number of Bands | & Length(Kb) \\
\hline 1 & 13 & 286 & 1144 \\
\hline 2 & 23 & 260 & 1040 \\
\hline 3 & 13 & 236 & 944 \\
\hline 4 & 18 & 222 & $\mathbf{8 8 8}$ \\
\hline 5 & 13 & 250 & 1000 \\
\hline 6 & 23 & 227 & 908 \\
\hline 7 & 18 & 243 & 972 \\
\hline 8 & 21 & 256 & 1024 \\
\hline 9 & 10 & 267 & 1068 \\
\hline 10 & 24 & 286 & 1144 \\
\hline 11 & 45 & 259 & 1036 \\
\hline 12 & 16 & 236 & 944 \\
\hline 13 & 24 & 234 & 936 \\
\hline 14 & 19 & 256 & 1024 \\
\hline 15 & 28 & 299 & 1196 \\
\hline 16 & 19 & 296 & 1184 \\
\hline 17 & 19 & 291 & 1164 \\
\hline 18 & 23 & 278 & 1112 \\
\hline 19 & 22 & 253 & 1012 \\
\hline 20 & 15 & 232 & 928 \\
\hline 21 & 22 & 238 & 952 \\
\hline 22 & 17 & 235 & 940 \\
\hline 23 & 26 & 273 & 1092 \\
\hline 24 & 17 & 242 & 968 \\
\hline 25 & 14 & 233 & 932 \\
\hline 26 & 27 & 257 & 1028 \\
\hline 27 & 22 & 235 & 940 \\
\hline 28 & 12 & 227 & 908 \\
\hline 29 & 14 & 231 & 924 \\
\hline 30 & 15 & 229 & 916 \\
\hline 31 & 15 & 233 & 632 \\
\hline 32 & 17 & 239 & 956 \\
\hline 33 & 14 & 223 & 892 \\
\hline 34 & 19 & 227 & 908 \\
\hline 35 & 20 & 240 & 960 \\
\hline 36 & 17 & 267 & 1068 \\
\hline 37 & 15 & 229 & 916 \\
\hline 38 & 26 & 282 & 1128 \\
\hline 39 & 23 & 250 & 1000 \\
\hline 40 & 28 & 237 & 948 \\
\hline 41 & 14 & 254 & 1016 \\
\hline 42 & 31 & 295 & 1180 \\
\hline 43 & 10 & 222 & 888 \\
\hline 44 & 12 & 231 & 924 \\
\hline 45 & 13 & 229 & 916 \\
\hline 46 & 12 & 237 & 948 \\
\hline 47 & 23 & 242 & 968 \\
\hline 48 & 17 & 228 & 912 \\
\hline
\end{tabular}


Construction of Oryza Sativa genome contigs

\begin{tabular}{|c|c|c|c|}
\hline Name of Contig | & Number of Bac Clone & Number of Bands | & Length(Kb) \\
\hline 49 & 23 & 229 & 916 \\
\hline 50 & 30 & 242 & 968 \\
\hline 51 & 28 & 227 & 908 \\
\hline 52 & 29 & 282 & 1128 \\
\hline 53 & 21 & 287 & 1148 \\
\hline 54 & 14 & 231 & 924 \\
\hline 55 & 18 & 242 & 968 \\
\hline 56 & 14 & 222 & 888 \\
\hline 57 & 18 & 223 & 892 \\
\hline 58 & 25 & 289 & 1156 \\
\hline 59 & 19 & 272 & 1088 \\
\hline 60 & 30 & 248 & 992 \\
\hline 61 & 20 & 241 & 964 \\
\hline 62 & 25 & 225 & 900 \\
\hline 63 & 19 & 241 & 964 \\
\hline 64 & 19 & 242 & 968 \\
\hline 65 & 28 & 322 & 1288 \\
\hline 66 & 30 & 340 & 1360 \\
\hline 67 & 31 & 306 & 1224 \\
\hline 68 & 42 & 597 & 2388 \\
\hline 69 & 30 & 325 & 1300 \\
\hline 70 & 21 & 232 & 928 \\
\hline 71 & 31 & 381 & 1524 \\
\hline 72 & 29 & 305 & 1220 \\
\hline 73 & 23 & 323 & 1292 \\
\hline 74 & 22 & 325 & 1300 \\
\hline 75 & 28 & 305 & 1220 \\
\hline 76 & 25 & 318 & 1272 \\
\hline 77 & 71 & 562 & 2248 \\
\hline 78 & 30 & 384 & 1536 \\
\hline 79 & 21 & 328 & 1312 \\
\hline 80 & 27 & 318 & 1272 \\
\hline 81 & 30 & 348 & 1392 \\
\hline 82 & 22 & 337 & 1348 \\
\hline 83 & 22 & 322 & 1288 \\
\hline 84 & 35 & 391 & 1564 \\
\hline 85 & 20 & 308 & 1232 \\
\hline 86 & 31 & 396 & 1584 \\
\hline 87 & 46 & 464 & 1856 \\
\hline 88 & 28 & 374 & 1496 \\
\hline 89 & 19 & 226 & 904 \\
\hline 90 & 23 & 293 & 1172 \\
\hline 91 & 19 & 227 & 908 \\
\hline 92 & 18 & 220 & 880 \\
\hline 93 & 16 & 242 & 968 \\
\hline 94 & 19 & 227 & 908 \\
\hline 95 & 21 & 289 & 1156 \\
\hline 96 & 17 & 241 & 964 \\
\hline
\end{tabular}


Tao QZ et al.

facilitate the location of genes of interest by positioning cloning; with the easy manupulation of BAC DNA, the BAC contigs will be served as an ideal backbone for DNA sequencing of the entire chromosome. Small errors may exist in contig build-ups, which could be corrected by mapping contigs to chromosomes by marker hybridization.

\section{ACKNOWLEDGMENT}

We would like to thank A Coulson of Sanger Center of Cambridge, England, LJ Shi of Shanghai Institute of Cell Biology, CAS, TP Wang of Shanghai Institute of Biochemistry, CAS, for their advice and encouragement; J Li of Shanghai Institute of Plant physiology, CAS, for his contribution to the modification of enzymatic reactions; CZ Zheng of Shanghai Institute of Organic Chemistry for his support in computer work; L Shen of Shanghai Institute of Organic Chemistry for her assistance in data analysis; X Hu, WH Tao, W Li, C Su, XL Zhang, WH Zhao of National Center for Gene Research, CAS, WZ Chang, ST Liu, WH Huang, YY Lu, FD Ni, HM Cao of Shanghai Institute of Biochemistry for their providing some useful fingerprint auto radiograms. GFH is the recipient of Rockefeller Foundation's Biotechnology Career Fellowship. this work was supported by funds from State Commission of Science and Technology, the Chinese Academy of Sciences and the Commission of Science and Technology of Shanghai.

\section{REFERENCES}

[1] Arumuganathan K, Earle ED. Nuclear DNA content of some important plant species. Plant Mol Biol Reporter 1991; 9:208.

[2] Hodges TK, Peng J, Lyznik LA, Koetje DS. Transformation and regeneration of rice protoplasts, PP. 155-174 in Rice Biotechnology, edited by Toennessen G and Khush G. CAB International, Tucson, Ariz. 1991.

[3] ibid.

[4] McCouch SR, Kochert G, Yu ZH, Wang ZY, Khush GS et al. Molecular mapping of rice chromosome. Theor Appl Genet 1988; 76:815.

[5] Kurata N, Nagamura Y, Yamamoto K, Harushima Y et al. A 300 Kilobase interval genetic map of rice including 883 expressed sequences. Nature Genetics 1994; 8:365.

[6] Sulston J, Mallett F, Staden R, Durbin R, Horsnell T, Coulson A. Software for genome mapping by fingerprinting techniques. CABIOS 1988; 4:125.

[7] Sulston J, Mallett F, Durbin R, Horsnell T. Image analysis of restriction enzyme fingerprint autoradiograms. CABIOS 1989; 5:101.

[8] Tao QZ, Zhao HY, Qiu LF, Hong GF. Construction of a full bacterial artificial chromosome (BAC) library of Oryza sativa genome. Cell Research 1994; 4: 127.

[9] Coulson A, Sulston J. Genome mapping by restriction fingerprinting, In: Genome Analysis: A practical approach, edited by Davies KE. IRL Press LTD Oxford UK 1988; PP. 19-40.

Received 2-11-1995. Revised 8-12-1995. Accepted 11-12-1995 